\title{
Guiando públicos: proposiçōes de consumo de Fortaleza como cidade-sede da Copa do Mundo FIFA 2014.
}

\section{Guiding audiences: propositions on consumption of Fortaleza as host city of 2014 FIFA World Cup}

\section{Emylianny Brasil Silva}

Mestre em Comunicação pelo Programa de Pós Graduação em Comunicação da Universidade Federal do Ceará (PPGCOM-UFC). Graduada em Publicidade e Propaganda pela Universidade Federal do Ceará. Integrante do Grupo de Pesquisa em Imagem, Consumo e Experiência Urbana (GICEU). Realiza pesquisa nas áreas de consumo, imagem e identidade de marca.

\section{Sílvia Helena Belmino}

Doutora em Comunicação pela Universidade de Brasília. Professora do Programa de Pós- Graduação em Comunicação (PPGCOM) e do Curso de Comunicação SocialPublicidade e Propaganda do Instituto de Cultura e Arte( ICA) da Universidade Federal do Ceará (UFC). Coordenadora do Grupo de Pesquisa em Imagem, Consumo e Experiência Urbana (GICEU).

\section{Resumo}

Na posição de cidade-sede da Copa do Mundo FIFA 2014 Fortaleza colocou-se em uma trajetória de exibição global de atributos. Um contexto de realocação de imagem apoiada em discursos de apresentação e orientação de consumo de Fortaleza. O questionamento em que se baseia este artigo é: Quem são os públicos e como eles são referidos nos guias de cidade-sede? A partir da metodologia de Análise Crítica do Discurso, foram analisadas seções de guias de cidade lançados para o megaevento.

Palavras-chave: cidade; consumo; megaevento.

\footnotetext{
Abstract

As host city of the 2014 FIFA World Cup, Fortaleza developed a global trajectory of display attributes. A context of image relocation supported by discourse and guidance relating to the consumption of Fortaleza. The question underlying the development of this article is : Who are the audience and how they are referred to in the guides of the host city? Through methodology of Critical Discourse Analysis, we analyzed sections of city guides released for the megaevent.

Keywords: city; consumption; megaevent.
} 


\section{Introduç̃̃o}

A cidade abriga historicamente a permanência e a mudança, constantemente atravessada pelas dimensões do espaço e do tempo, materializa e espelha os modelos e práticas das sociedades que nela residem ou que por ela transitam. Este trabalho parte da noção de que na contemporaneidade o espaço urbano assimila em si: a fragmentação cotidiana, os valores da sociedade de consumo (BAUDRILLARD, 2007), que é moldada para os indivíduos convertidos em consumidores (BAUMAN, 2008), e as negociações que a cidadania (CANCLINI, 2008) requer para permanecer.

No que se refere ao consumo, as cidades acumulam dupla função: a de local em que o consumo de bens materiais e simbólicos se realiza e a de espaço consumido diretamente. Ao descrever a cidade como um tecido urbano, que compõe um ecossistema intrincado e estabelece um modo próprio de viver, Henri Lefebvre (2001) traz à tona a fragmentação desta teia e sua tendência em ocultar tensões, enquanto produz sistemas de valores atinentes da sociedade dita urbana. $\mathrm{O}$ autor estabelece que, em meio à diferença e à constante mudança, a cidade não evanesce, transforma-se:

(a cidade) Não contém apenas monumentos, sedes de instituições, mas também espaços apropriados para as festas, para os desfiles, passeios, diversões. O núcleo urbano torna-se, assim, produto de consumo de uma alta qualidade para estrangeiros, turistas, pessoas oriundas da periferia, suburbanos. Sobrevive graças a este duplo papel: lugar de consumo e consumo do lugar. (LEFEBVRE, 2001, p.20)

Há a afirmação de um espaço de consumo que busque atender às demandas de potenciais consumidores, sejam eles permanentes ou de passagem. Afirmação que guarda proximidade com as noções de compra de bens descritas por Gilles Lipovetsky (2007), o autor enuncia que se vive em uma sociedade de hiperconsumo, uma ordenação em que o consumo está dividido

(...) ordenando-se em torno de dois eixos antagonistas: de um lado, a compracorveia ou compra-prática; do outro, a compra hedônica ou compra-festa, que diz respeito tanto aos produtos culturais quanto a muitos bens materiais (carro, moda, mobiliário, decoração etc.). (LIPOVETSKY, 2007, p.66.)

Os dois modos de compra estão presentes nas práticas de consumo urbano, que são replicadas e coexistem sem necessariamente antagonizarse, mas em constante processo de adaptação às transformações e espetacularizações do cotidiano e do espaço.

Desenvolvendo a relação da cidade com o multifacetado conceito de pós-modernidade, Fernanda Sánchez (2010) articula uma série de contextos e práticas que tem contribuído para a conversão do lugar de consumo em cidade-mercadoria. Para a autora, são processos que estão presentes quando 
a mercadoria de que se trata é a própria cidade. Os esforços de conversão da cidade em produto desejável e disponível no mercado de cidades modelo, enquadradas em padrões de 'viabilidade' global, tem ganhado contornos concorrenciais, em que as cidades modificam-se e (res)significam seus espaços e sua imagem para existir em um circuito de atração de atenção, pessoas e investimentos.

"Colocar as cidades no mapa do mundo" passou a ser uma meta recorrente dos governos locais, um objetivo ordenador das "ações estratégicas" que concentram na cidade - mercadoria a possibilidade de "transcender as crises" produzidas pela reestruturação econômica e de construir um futuro de progresso e recuperação econômica sintonizado com as exigências da nova ordem mundial, de modo a viabilizar o crescimento econômico em novos parâmetros. (SÁNCHEZ, 2010, p.51)

Um dos percursos de conversão da cidade em mercadoria e exacerbação das proposições de consumo urbano para a integração ao circuito mundial está na realização de eventos detentores de visibilidade mundial. Os megaeventos são realizações que requerem estruturas específicas, realização periódica e potencial de alcance mundial. O megaevento é categoria ainda sem conceituação precisa, as existentes divergem quanto às características capazes de determinar o que constituiria ou não um megaevento, a maior parte dos estudos a respeito destas realizações direciona-se à análise do legado deixado para os locais de realização (TAVARES, 2011). O Brasil sediou uma série de 'megaeventos', como os Jogos Pan-Americanos de 2007, edições bienais do Rock in Rio, a Copa do Mundo FIFA 2014 e receberá as Olimpíadas de 2016, todos estes acontecimentos trazem alterações espaciais e simbólicas para os lugares em que ocorrem.

A Copa do Mundo de 2014 ficou a cargo do Brasil desde 2007, o anúncio das cidades-sedes foi feito em maio de 2009, depois de adiamentos e acirrada concorrência pela posição entre as capitais brasileiras. Exibindo qualidades e garantindo obras e prazos para alterações estruturais e para a entrega de estádios padrão FIFA, estas cidades viveram percursos distintos de convencimento externo e interno. Por fim, doze sedes foram selecionadas, entre elas, Fortaleza. O evento esportivo organizado por uma entidade internacional (FIFA) encarregou estas cidades de responsabilidades de realização do megaevento e cobrou que suas exigências fossem cumpridas, requerendo o alinhamento de governos, iniciativa privada e dos cidadãos. Trata-se de um contexto de tensionamentos e de negociações de razões e espaços, visando a atração de turistas/torcedores, a diferenciação de caráter qualificador em relação às demais sedes e o endosso da população.

Os anos de preparação contaram com estratégias de promoção destas cidades-sedes, foram diversas as campanhas e projetos realizados, principalmente pelo Ministério do Turismo, Ministério dos Esportes e pela 
EMBRATUR, entre eles pode-se destacar: a série de vídeos "Brasil 2014 A viagem da Copa começa aqui" "1 lançada em 2010, trazia depoimentos de artistas, empresários e gestores locais indicando as 'qualidades únicas' de suas respectivas cidades; e uma iniciativa inaugurada às vésperas do mundial, a plataforma Visit Brasil,2 que oferece um guia para o turista do que há de "melhor" em diversos destinos turísticos brasileiros, ressaltando as cidadessede.

Poucos meses antes do evento começaram a ser lançados, por veículos midiáticos, por empresas privadas e pelos governos, guias das cidadessede, ressaltando atributos e propondo percursos para os consumidores do evento. Consideramos os guias neste artigo como produtos que condensam características informacionais e publicitárias, e propõem itinerários e experiências de consumo ao interlocutor. Tratam-se de construções que editam as possibilidades da cidade, exaltando e escondendo opções de consumo urbano, servindo assim de construtores de percepção da cidade no contexto de realização do megaevento. $\mathrm{O}$ direcionamento destes guias tem foco no turista, mas não deixam de considerar o habitante.

Estabelecidos os pontos de partida deste trabalho, coloca-se como questão: Quem são os públicos e como estes aparecem nos discursos referentes à Fortaleza, presentes nos guias das cidades-sede? Foram analisados dois guias online, o Guia das Cidades-Sedes (Portal da Copa - Governo Federal) e o Portal Fortaleza-Ceará 2014 (produzido em parceria pelas secretarias especiais da copa). Utilizando a Análise Crítica do Discurso, proposta por Norman Fairclough (2001), pretende-se perceber como esses públicos aparecem no texto, como são referidos explicita e implicitamente, e problematizar quais as implicações dessas menções. Um material que interessa potencialmente aos turistas nacionais e estrangeiros e aos habitantes, que são em muitos pontos resumidos na alcunha de torcedores, objetiva-se compreender qual o papel dos públicos nos discursos orientadores deste espetáculo do consumo e de 'reinvenção' urbana.

\section{Fortaleza cidade-sede: guias como proposições de consumo.}

A capital cearense possui aproximadamente dois milhões e meio de habitantes, ordenou-se ao redor de um forte e é espaço que abriga em si profundas diferenças. Um dos destinos turísticos mais visitados nacionalmente é também apontado como a sétima cidade mais perigosa do mundo. A posição de cidade-sede trouxe para este contexto, mais uma pauta de reafirmação turística e de diferenciação urbana.

Inserida em uma lógica de reestruturação e 'vitrinização' de 
viabilidade e atributos de diferenciação, a cidade-sede é ambígua, esforça-se para adequar-se a um padrão que garanta aprovação internacional, ao mesmo tempo em que precisa destacar-se em relação às demais cidades que cumprem (ou eventualmente poderiam cumprir) as mesmas funções. $\mathrm{O}$ fenômeno das cidades-mercadorias pode ser percebido em escala global, pensando na perspectiva da América Latina é um projeto recente, que apoiado nas proposições do branding city e do marketing de lugares (KOTLER. et al, 2006) tem conduzido as cidades a projetos urbanos voltados para a construção ou consolidação de projeção internacional, com a viabilidade para o visitante, com a estrutura para grandes eventos, percebendo o cidadão local como parte do processo e não como 'consumidores' principais do espaço urbano. "As políticas urbanas voltadas para a inserção competitiva da cidade no mundo constroem uma relação entre o local e o global conforme lógicas que são de interesse de grupos dominantes" (SANCHEZ, 2010, p.276). No que concerne ao megaevento, são projetos que partem do principio que a aprovação internacional, a atração de visitantes e a visibilidade são suficientes para concretizar a aceitação por parte dos cidadãos.

A cidade surge como local de acirramento dos impulsos de consumo, para Jean Baudrillard (2007) "o discurso da cidade é a própria concorrência" (p.64), relaciona esta disputa ao acirramento de desejos, estímulos, aceitação, erotização e constante negociação de sentidos, que quer diferenciar para destacar-se nas relações de concorrência, mas não ao ponto de afastar-se de valores estatutários. Relações que no enunciado do autor são incentivadas e baseadas na pluralidade urbana, é uma visão da cidade como ente indispensável à sociedade de consumo: vê o urbano como instância, que a partir de uma linguagem própria, adequa-se ao consumo infindável baseado na infinitude dos desejos e das necessidades que se ancoram no tecido urbano ${ }^{3}$.

Nestor García Canclini pensa essa relação e enxerga o consumo como "um conjunto de processos socioculturais em que se realiza a apropriação e os usos dos produtos" (CANCLINI, 2008, p.60), uma perspectiva que amplia a noção de respostas automáticas a um tipo de contexto econômico préconcebido. Do mesmo modo que o mercado se transforma para englobar mais e mais instâncias da vida e converter a totalidade da vivência em atos de consumo, o consumidor está inserido nesta lógica e também desenvolve mecanismos para pensar o consumo.

O guia de cidades surge como um promotor deste processo, um aglutinador de informações e propagador de discursos que tem por função apresentar o lugar e orientar o consumidor do espaço. No contexto do megaevento é ferramenta de promoção da cidade, das obras, da cultura local e de ofertas de consumo material e simbólico do espetáculo esportivo. Irlys Barreira (2010) ao pensar as narrativas e memórias de Berlim a partir de guias 
turísticos, apresenta a seguinte definição:

Um guia ou catálogo de informações sobre a cidade é, como diz o próprio nome, indicativo de um caminho contrário à atitude de caminhantes que se deixam vagar a esmo (...). Os materiais informativos funcionam, nesse sentido, como uma direção para evitar "caminhos incertos" ou desvios de um modo planejado de conhecer a cidade. (BARREIRA, 2012, p.39)

Os guias são por tanto edição do tecido urbano, textos e imagens que visam sintetizar história, cultura e funcionalidade da cidade que se propõe a descrever. São seleção de pontos turísticos, fatos curiosos, memórias do lugar para dar a conhecer e caracterizar a multiplicidade e a riqueza de uma cidade, a partir dos excertos incluídos em uma narrativa de orientação de consumo. Além disso, marcam em seu conteúdo um determinado momento espacial e temporal da cidade. É proposição mediadora entre experiência urbana real e a experiência planejada, moldada e apresentada como 'melhor' opção.

Tendo por objeto guias de cidade, elaborados profissionalmente e disponibilizados durante o contexto de realização de um megaevento esportivo, são produtos que buscam abarcar informação e promoção de um espaço em negociação. Atreladas ao governo federal, estadual e municipal não são por si produtos midiáticos, mas carregam em seus discursos características de oficialidade, mescla o informacional e o publicitário, um hibrido propondo discursos mediadores do consumo urbano.

No contexto do megaevento, o guia de cidades-sede cumpre uma função semelhante ao abordar positivamente a trajetória de preparação e os resultados alcançados, pouco antes e durante a realização do megaevento. Seleciona do 'repertório' urbano as histórias e características que 'merecem' narração em uma estrutura discursiva apoiada na estrutura governamental, em geral detentora de autoridade, gerando a noção de 'versão oficial', aparentemente mais válida e certamente mais conhecida que as demais narrativas correntes nas ruas, nos bairros, nas comunidades e contadas pelos cidadãos.

\section{Análise Crítica do Discurso dos guias de cidade: as proposições de sentido entre Fortaleza e 'seus públicos'.}

A Análise Critica do Discurso (ACD) é um modelo teórico-metodológico qualitativo, proposto pelo linguista inglês Norman Fairclough (2001). O autor propõe a abordagem do discurso como prática, não apenas refletindo ou representando o social, e sim ajudando a constituí-lo. "A ADC estuda textos e eventos em diversas práticas sociais, propondo uma teoria e um método para descrever, interpretar e explicar a linguagem no contexto sócio histórico" (MAGALHÃES, 2005, p.3). A partir da formulação de uma teoria social 
do discurso, Fairclough (2001) busca unir com equilíbrio as dimensões da linguagem e da prática social localizadas em contextos específicos.

A ACD mescla elementos de diversas disciplinas para compor uma proposição de análise tridimensional que trata o discurso como: texto, prática discursiva e prática social. No interior de cada uma dessas dimensões encontramse orientações teóricas e subcategorias de análise, que devem direcionar a realização da análise requerendo diversas idas e vindas ao texto, passando por diversos estágios de interpretação e amadurecimento de afirmações e inferências. Fairclough (2001) propõe as seguintes dimensões e subcategorias:

- Análise Textual: vocabulário, coesão, transitividade, gramática, tema, modalidade, polidez, estrutura textual;

- Análise da prática discursiva: força dos enunciados (tipos de atos de fala), coerência, cadeias intertextuais, coerência, condições da prática discursiva, interdiscursividade e a intertextualidade;

- Prática Social: possíveis níveis de análise matriz social do discurso, ordens de discurso, efeitos ideológicos e político do discurso.

A seleção de categorias e a ordem em que cada dimensão aparece na análise estão atreladas aos objetivos do trabalho e ao corpus da pesquisa. Para este artigo foram selecionados dois guias de cidades (Guia de Cidades-Sede - Portal da Copa; Portal Fortaleza - Ceará 2014) lançados on-line, compõem discursos mistos de divulgação e informação. Destes guias serão analisadas as seções referentes à cidade de Fortaleza, visando identificar as presenças, ausências e função do público nesses produtos.

O Guia de Cidades-Sede foi lançado no Portal da Copa em abril de 2014, ferramenta oficial de informações sobre o mundial do Governo Federal, trazia páginas para as 12 sedes e conteúdos divididos nas seguintes subseções: Aeroporto; Arena; Cultura; Gastronomia; Mapa; Turismo; Distâncias; Guia do Passageiro; Cartazes Oficiais, Telefones Úteis; Transporte; Seleções; Tabela de Jogos. Pelo maior número de subseções e algumas delas padronizadas para todas as cidades-sede, foram enfatizadas aquelas equivalentes ao outro guia analisado, possibilitando maior coerência na perspectiva comparativa.

O guia Portal Fortaleza Ceará 2014, foi lançado um mês antes do evento pela parceria da Secretaria Especial da Copa do Governo do Estado e Secretaria Especial da Copa de Fortaleza. Tratava-se de um hotsite que funcionou como um condensador de informações e notícias do mundial em Fortaleza, durante o período de realização. A seção referente à Fortaleza estava dividida nas seguintes subseções: Localização; Transporte; Histórias de Fortaleza; Onde; e FIFA FAN FEST.

Estabelecido o corpus, passou-se à exploração inicial, e posterior 
definição de categorias de análise para cada uma das dimensões do modelo de Fairclough (2001), conforme análises a seguir.

\section{Prática Social - Ordens de Discurso}

O trabalho foi iniciado pela dimensão da prática social, pois das três dimensões é a parcela do discurso que se encontra 'fora' do corpus. Recorrendo à fontes de informação secundárias, capazes de fornecer falas dos responsáveis pelos discursos veiculados nestes guias, pretende-se, por meio de suas afirmações, estabelecer lugar do discurso ocupado pelos produtores e relações estabelecidas por elas com o público.

Por ocasião do lançamento do Portal Fortaleza Ceará 2014 Ferrúcio Feitosa, Secretário Especial da Copa 2014, descreveu a plataforma como a apresentação 'do melhor que temos a oferecer':

O hotsite 'dá boas-vindas a todos os amantes de futebol que estarão na cidade para assistir às partidas da Copa do Mundo. Ele servirá como porta de entrada para o turista se planejar e curtir ao máximo o que de melhor temos a oferecer. Nossa cultura, nossa hospitalidade e nossa alegria (Fonte: Secopa ${ }^{4}, 13$ de maio de 2014).

O trecho foi divulgado no site da Secopa (Secretaria Especial da Copa do Estado), por ocasião do lançamento do hotsite. Uma fala oficial, programada e pensada para transmitir a melhor percepção do guia ao público alvo e, também, aos fortalezenses, já que a percepção positiva do evento pelos cidadãos (e potenciais eleitores) é interesse do governo estadual. A oferta é feita a todos os amantes de futebol e aos turistas, que tem no trecho valor de sinônimo, mas abrem margem para a inclusão implícita dos habitantes como 'torcedores'. O fortalezense aparece outra vez na menção à hospitalidade, que depende diretamente da população local e na alegria, também característica subjetiva repetidamente relacionada ao cearense.

O trecho referente ao Guia das Cidades-Sede foi veiculado no próprio Portal da Copa, por ocasião do lançamento e diferencia-se do anterior por não apresentar uma citação direta de fonte oficial. É um texto de divulgação, com características de release, que informa a existência do guia do modo como seus produtores desejam comunicar.

Muito além de 64 partidas entre 32 seleções nacionais, a Copa do Mundo é uma grande oportunidade para conhecer o que há de melhor no Brasil, em especial nas 12 sedes do evento. Para ajudar turistas nacionais e estrangeiros a aproveitar ao máximo esse período, o Portal da Copa preparou um guia detalhado das cidades que receberão os jogos. (Fonte: Portal da Copa ${ }^{5}, 23$ de abril de 2014).

O posicionamento do guia do portal federal refere-se somente aos turistas nacionais e estrangeiros e não estabelece inferências explícitas ou implícitas com os habitantes de cada uma das cidades-sede. Traz em sua 
afirmação um discurso direcionado ao publico em trânsito pela cidade-sede, que deve utilizar o guia para consumir o que há de melhor no país.

Fairclough (2001) ao tratar das práticas discursivas relaciona estas com dinâmicas de mudanças nos discursos, social e cultural, tendências gerais de modificação. A mudança aqui relaciona-se ao contexto de realização da Copa, que direciona o texto para uma ocorrência específica. No que concerne ao público-alvo, linguagem e mesmo afirmação de identidade (hospitalidade/ humor), ou mercantilização urbana, ou diálogo com o interlocutor não há alteração do discurso corrente, esperado por uma sede, com cidades-modelo, que antes da unicidade, precisam demonstrar viabilidade.

O lugar de fala modifica sutilmente a posição do residente da sede, apesar de implicitamente, ele está presente no discurso da instância estadual/ municipal, enquanto no nacional é invisível. Aspecto ligado à escala do discurso, mas também à diferença estrutural dos produtos, que enquanto o primeiro é específico e pensado pelo estado e pelo município retratado, o outro é generalista e busca não estabelecer diferenciações qualificadoras entre as sedes, adotando postura elogiosa em relação ao país.

\section{Texto - Tema}

$\mathrm{Na}$ dimensão textual a categoria de análise empregada foi a de tema, que é definido por Fairclough (2001) como “(...) o ponto de partida do (a) produtor (a) do texto numa oração e geralmente corresponde ao que pode ser considerado (o que não significa que realmente seja) 'informação dada'." (FAIRCLOUGH, 2001, p.227). Partindo do objetivo do artigo que é perceber a presença do público no discurso dos guias, as proposições e temáticas recorrentes ou inusitadas, perceptíveis por meio da estruturação da informação, ajudam a compreender que público é esse e de que modo aparece.

O Portal Fortaleza Ceará 2014, apresenta menções aos possíveis públicos (turistas, fortalezenses, torcedores) em apenas duas (Histórias de Fortaleza e FIFA FAN Fest) das cinco seções do menu Fortaleza:

Fortaleza é marcada por um litoral de 34 quilômetros que encanta moradores e turistas e por uma população hospitaleira, acolhedora e criativa (...) a Beira-Mar e a Praia do Futuro se destacam, onde fortalezenses e turistas podem caminhar ao longo do calçadão. (...) receptiva a todos que queiram desfrutar de sua beleza natural única e de sen povo forte e batalhador, que faz jus ao nome de Fortaleza. (Fonte: Portal Fortaleza Ceará 2014 - Seção: Histórias de Fortaleza)

(...)o FIFA Fan Fest promete ser a segunda arena onde os torcedores poderão acompanhar os jogos como se estivessem no Estádio Castelão (...) uma oportunidade para turistas, fãs de futebol e torcedores locais se confraternizarem, (...) O FIFA FAN Fest fortalece e democratiza a experiência dos torcedores da Copa do Mundo, atraindo 
milhões de pessoas também fora dos estádios. (...) O Aterro de Iracema oferecerá aos moradores e turistas de Fortaleza o espaço ideal para assistir às partidas do Mundial. (Fonte: Portal Fortaleza Ceará 2014 - Seção: FIFA FAN Fest)

Nas duas seções as abordagens são fortemente valorativas, com uso de adjetivos e uma linguagem característica do discurso publicitário. $\mathrm{Na}$ seção histórias de fortaleza têm-se três temas atrelados a três públicos: o morador, o turista e o fortalezense. Na primeira menção, turistas e moradores aparecem em mesmo patamar, encantados pela beleza do lugar; na segunda menção os 'moradores' são substituídos por fortalezenses e permanecem no mesmo patamar, é só nas menções de população hospitaleira e povo forte e trabalhador que surge um desvio na temática, pois o habitante que consome a cidade também carrega a responsabilidade de compor a oferta de cidade mercadoria feita ao turista.

Na seção FIFA FAN Fest as menções ao público tem por função evidenciar a igualdade de oferta e possibilidade de participar do evento, é o único excerto que efetivamente convida o morador para a Copa do Mundo, já que na anterior o texto é genérico e não faz referência à realização do megaevento. Turistas, fãs de futebol e torcedores locais são resumidos como torcedores que podem partilhar um espaço democrático de consumo do evento.

"Na mesa do sertanejo"; "Boa parte dos pratos é encontrada em toda a região, mas o visitante pode encontrar, em cada um dos nove estados, modos especiais de preparo." (seção Gastronomia).

"Fortaleza - captura os visitantes em uma mistura de luminosidade e praias. (...) Os moradores locais estão sempre dispostos a contribuir com dicas ou explicações sobre as delícias regionais. (...) o programa de moradores e turistas é se reunir em bares e restaurantes" (seção Turismo)

No Guia das Cidades-Sede as menções aos públicos estão presentes em todas as seções analisadas, seja como população com indicação de números de habitantes (seção Turismo e Cultura), como passageiros (seção transportes), como sertanejo, visitante e vaqueiro (Gastronomia'), porém a estrutura dos temas é predominante distanciada, com uma linguagem, que embora qualifique, esforça-se para manter a objetividade. O oferecimento para consumo visando o público alvo da cidade aparece apenas na seção turismo, em que há semelhanças com as menções das seções do Portal Fortaleza Ceará 2014, pois trazem moradores e visitantes como consumidores de certos espaços da cidade, acumulando os papéis de consumidor e atributo qualificador da experiência urbana. 


\section{Prática Discursiva - Intertextualidade Manifesta}

A prática discursiva é a dimensão da ADC que contribui fortemente para o entendimento do discurso como prática intrincada à produção e ao social. A intertextualidade é dita por Norman Fairclough (2001) como central na sua proposição metodológica

Trata das referências, pontos de contato, citações e retomadas que um texto faz de outros textos ou de outros lugares de discurso. Na contemporaneidade em que os valores, conteúdos e gêneros parecem progressivamente misturados e difíceis de discernir a intertextualidade é presença constante. O autor estabelece classificações: intertextualidade manifesta, cadeias intertextuais, interdiscursividade. A opção pela intertextualidade manifesta faz por tratar-se da área que está entre a prática discursiva e o texto, "levanta questões sobre o que vai na produção de um texto, mas também diz respeito às características que estão manifestas na superfície do texto.” (FAIRCLOUGH,2001, p.285). Neste trabalho a opção pela intertextualidade discursiva faz-se sob dois eixos: a representação discursiva e a pressuposição, esta contribuindo para a problematização do lugar do público no discurso dos guias, e aquela completando as reflexões empreendidas nos tópicos anteriores.

No Portal Fortaleza Ceará 2014 traz uma representação de público muito próxima da do discurso publicitário, utilizando-se de elementos de convencimento e elogio à cidade e aos habitantes, para atrair o turista e, assim, todos à consumirem as belezas naturais, a cultura, o artesanato e a hospitalidade do povo fortalezense. Dentro das páginas há referências diretas a conteúdos externos, como páginas de pontos turísticos, a programação do FIFA FAN Fest e os itinerários de ônibus, todos incorporados na estrutura textual, mas direcionandos para 'fora' do guia. As proposições que ficam são: a de turista como público-alvo principal, o habitante ocupando o duplo papel de consumidor e atributo qualificador e a tentativa de sugerir uma democratização dos espaços e da possibilidade de consumir o evento em si na seção FIFA FAN Fest, afinal o consumo direto do evento foi restrito ao espaço físico do estádio Castelão e ao poder econômico para adquirir os ingressos. Na proposição relativa ao FIFA FAN Fest cabe ressaltar a parceria com a Rede Globo e a FIFA, que trazem para dentro do guia outros lugares do discurso que não a dos governos locais,

Já o Guia das Cidades-Sede traz representações gerais dos públicos, com orientação para o turista reforçada em toda a sua construção, traz o habitante da cidade-sede representado predominantemente como contexto, pano de fundo de um espetáculo feito para o visitante. Quando incluído nas proposições de consumo, limita-se ao que já é por ele consumido deste espaço, como relato de experiência local que vale a pena replicar, porém sem dar voz 
aos atores dessas experiências. Traz nas seções uma série de referências diretas a outros conteúdos também de fontes ligadas ao governo federal, como o Instituto Brasileiro de Turismo (EMBRATUR) e o Instituto do Patrimônio Histórico e Artistico Nacional( IPHAN), não variando, assim, os lugares do discurso. Um detalhe curioso está na seção gastronomia o indício de um texto que não foi preparado especificamente para o guia: "Como a Copa das Confederações e o Mundial de 2014 ocorrerão em junho, há grandes chances de os turistas poderem aproveitar os festejos típicos, que incluem os seguintes quitutes". O trecho faz menção à Copa das Confederações no futuro, e o evento foi realizado em junho de 2013, muito antes do lançamento do material. Apesar de manter um caráter predominantemente informativo, em suas generalizações traz o discurso do exotismo, da alegria e da natureza, historicamente atrelados à imagem do país, não particulariza, apresenta e valora a partir de um discurso generalizante.

\section{Considerações Finais}

A presença do público nos guias de cidade-sede é discreta e faz-se muito mais em favor do visitante que do morador. Pela origem de produção de ambos os guias, fruto de iniciativas governamentais diretamente envolvidas na realização do evento, explica-se a replicação de qualificadores generalizantes e a pouca ou nenhuma variação nos lugares do discurso. A voz presente nos dois textos que apresentam e orientam a experiência urbana nas cidades-sede é monotônica e singular. O turista, o torcedor e o fortalezense confudem-se em parte das menções e quando diferenciam-se faz-se de forma sutil, para encorajar determinado percurso, ou assegurar a viabilidade de determinada sugestão de consumo oferecida pelos guias.

O fortalezense aparece como qualificador em ambos os guias, com objetividade ou persuasão. É inserido nos contexto de consumo e interação com os turistas e, em certo ponto, convidado a participar do megaevento ainda que indiretamente, mas não há voz. A história, a cultura, o artesanato, as praias e até a alegria e a hospitalidade falam por ele em uma construção de um discurso unificador. Ainda na introdução deste trabalho tratou-se o caráter duplo do consumo urbano, no discurso do guia ele traz características de unificidade quando em relação ao habitante do lugar, que por sua vez mescla-se à paisagem aproximando-se de uma atributo qualificador das potencialidades de consumo do lugar.

Pode-se, então, afirmar que na condição de público consumidor os guias de cidade apresenta o turista como o cliente almejado que está de passagem sem grandes perspectivas de retornar, e que concentra as principais atenções. 
Já o morador local surge predominantemente como contexto, paisagem, até mesmo quando convidado a consumir.

\section{Notas}

1

Lançada em 2010, a série de doze vídeos reunia autoridades e artistas para descrever e divulgar suas cidades de origem, o vídeo carrega um tom de concorrência na medida em que as falas tentam diferenciar e destacar uma cidade em relação às demais. $\mathrm{O}$ de Fortaleza destaca o mote "verão e bom humor o ano todo": http://www.youtube.com/watch?v=olk2kbsqNTs

Visit Brasil, lançado em 20 de maio de 2014 às vésperas do Mundial, serve de vitrine e orientação de consumo dos destinos turísticos brasileiros e das cidades-sedes http://www.visitbrasil.com/

3

"O tecido urbano pode ser descrito utilizando o conceito de ecossistema, unidade coerente constituída ao redor de uma ou de várias cidades, antigas ou recentes. (...) Ele é o suporte de um "modo de viver" mais ou menos intenso ou degradado: a sociedade urbana." (LEFEBVRE, 2001, p.19).

4 Disponível em: http://www.secopa.ce.gov.br/index.php/ sala-imprensa/44265-lancamento-do-hotsite-oficial-marca-30-dias-para-copa-domundo-em-fortaleza. Acessado em 20 de novembro de 2014.

5 Disponível em: http://www.copa2014.gov.br/pt-br/noticia/ portal-da-copa-lanca-um-guia-das-cidades-sede?language=pt-br. Acessado em 20 de novembro de 2014

6

A seção gastronomia engloba todos os estados do nordeste em um texto de apresentação para o livro Aromas, Cores e Sabores do Brasil. 


\section{Referências Bibliográficas}

BARREIRA, Irlys. Cidades narradas: memória, representações e práticas de turismo. Campinas, SP: Pontes Editores, 2012.

BAUDRILLARD, Jean. A Sociedade de consumo. Rio de Janeiro: Elfos; Lisboa: Edições 70, 2007.

BAUMAN, Zygmunt. Vidapara consumo: a transformação das pessoas em mercadorias. Rio de Janeiro: Jorge Zahar Ed. ,2008.

FAIRCLOUGH, Norman. Discurso e mudança social. UnB, 2001.

GARCÍA CANCLINI, Nestor. Consumidores e cidadãos. Rio de Janeiro: UFRJ, 2008.

KOTLER, P.; GERTNER, D.; REIN, I; HAIDER, D. H., Marketing de Lugares: como conquistar crescimento de longo prazo na América Latina e no Caribe. São Paulo: Prentice Hall, 2006.

LEFEBVRE, H. O Direito à Cidade. São Paulo: Centauro, 2001.

LIPOVETSKY, Gilles. A felicidadeparadoxal: ensaio sobre a sociedade de hiperconsumo. São Paulo: Companhia das Letras, 2007.

MAGALHAES, Izabel. " Introdução: a análise de discurso crítica.”, DELTA [online]. 2005, vol.21, pp. 1-9.

SÁNCHEZ, Fernanda. A reinvenção das cidades para um mercado mundial. Argos, Editora Universitária, 2010.

TAVARES, Otavio. Megaeventos Esportivos. Movimento. Porto Alegre, v.17, n.3, p.1135. 2011. 